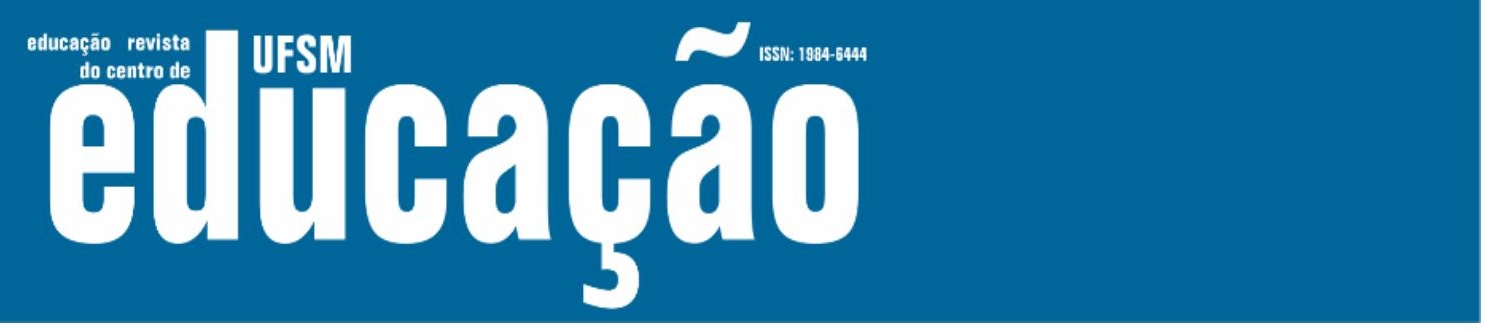

ISSN: 1984-6444 | http://dx.doi.org/10.5902/1984644440290

\title{
O FERESP como novo intelectual coletivo na formulação das políticas para a educação superior brasileira ${ }^{1}$
}

FERESP as a new collective intellectual in the formulation of policies for Brazilian higher education

Fabíola Bouth Grello Kato

Professora doutora na Universidade Federal do Pará. Belém, Pará, Brasil.

fabiola_kato@hotmail.com - https://orcid.org/0000-0002-5396-9128

Ana Paula Batista da Silva Brito

Doutoranda na Universidade Federal do Pará. Belém, Pará, Brasil.

anapaula.pbs@hotmail.com - https://orcid.org/0000-0001-6639-9083

Recebido em 01 de outubro de 2019

Aprovado em 13 de junho de 2020

Publicado em 18 de novembro de 2020

\section{RESUMO}

Este artigo analisa a criação e o papel que vem exercendo o Fórum das Entidades Representativas do Ensino Superior Particular (FERESP), assim como as ações concretas desta entidade como a grande articuladora dos interesses do setor privado a partir de sua atuação junto aos órgãos deliberativos que propõem os projetos e leis educacionais no Estado Brasileiro como o Ministério da Educação (MEC) e o Parlamento. Buscamos estabelecer relações de identidade entre a agenda do Fórum, construída nos últimos dez anos, e as alterações ocorridas na política para a educação superior. Trata-se de pesquisa de caráter documental e bibliográfica realizada a partir da análise de 11 cartas (2008-2018) deliberativas publicadas pela entidade e que representam, ano a ano, a síntese de suas propostas decorrentes de suas reuniões anuais, além da análise de outros documentos extraídos do seu site oficial publicados pela entidade entre os anos de 2008 a 2018, a partir da sua criação com objetivo de analisar as proposições e modificações nas legislações brasileiras. A pesquisa concluiu, a partir da leitura das cartas e documentos, que esta entidade atua como um intelectual orgânico de base coletiva, induzindo a construção de uma agenda de políticas públicas para a educação superior, com vistas ao favorecimento das instituições privadas, sobretudo, as privadas-mercantis havendo uma relação de identidade entre as recentes reformulações políticas/jurídicas para o setor privado da educação superior e as demandas oriundas dos congressos do Fórum, lócus prioritário de publicização das demandas provenientes dessa entidade.

Palavras-chave: Ensino Superior privado; FERESP; Políticas Públicas Educacionais. 


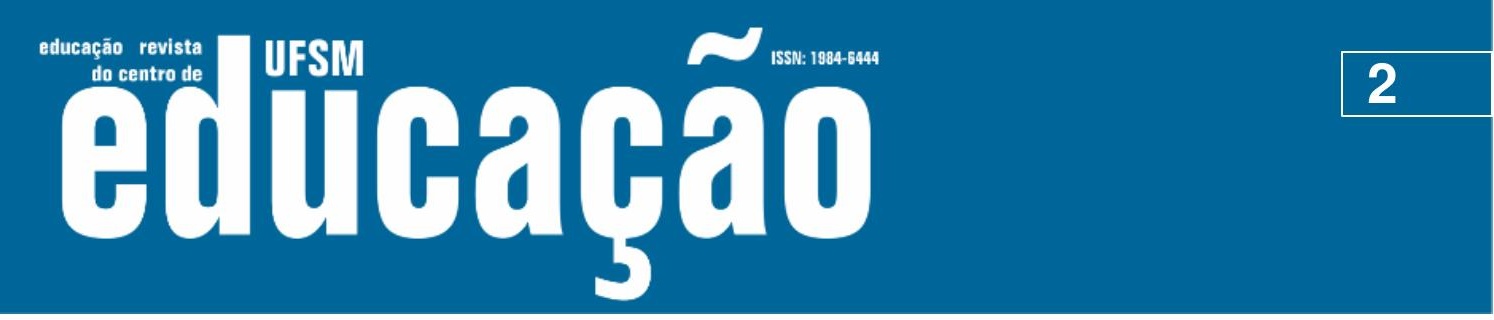

ISSN: 1984-6444 | http://dx.doi.org/10.5902/1984644440290

\section{ABSTRACT}

The present article analyzes the creation and the role that the Forum of Private Higher Education Representative Entities (FERESP) has been playing, as well as the concrete actions of this entity as a great articulator in favor of the private sector's interests from a position of action alongside the deliberative body that proposes the educational projects and laws in the Brazilian State like the Ministry of Education (MEC) and the Parliament. We seek to establish a connection between the Forum's agenda, built in the last ten years, and the changes made in the policies concerning higher education. The study has been made through documentary and bibliographic research that analyzed 11 deliberative letters (2008-2018) published by the entity in question that represent, year by year, the synthesis of the propositions derived from these yearly meetings, plus the analysis of other documents extracted from the entity's official site published throughout the years 2008 until 2018, starting from its creation with the objective of analyzing the propositions and modifications in Brazilian policies. The study concludes, after careful reading of the letters and documents researched, that this entity acts as an organic intellectual collective, inducing the construction of a public policy agenda for higher education, favoring private institutions, above all, privatemarket institutions; existing an identity relation between the most recent reformulations in politics/laws for the private sector of higher education and the demands originated from the Forum's congresses, primary locus of publicization of the demands stemmed from this entity.

Keywords: Private higher education; FERESP; Public Education Policies

\section{Introdução}

O aprofundamento do processo de privatização da educação superior no Brasil tem assumido variadas feições nos últimos trintas anos, orientados, sobretudo, pelas alterações na economia e na política, sendo parte de um amplo processo de reformas institucionais que objetivam, em última instância, alterar o pacto social brasileiro, principalmente a relação entre o Estado e a sociedade, sobretudo, no que toca a escolha no uso do seu fundo público. Este amplo processo de alterações institucionais, com origem no Estado, vem conduzindo à conclusão de que a reforma na educação é parte desse processo "[por] se trata[r] de mudanças no ordenamento jurídico-educacional que dão seguimento às modificações dos projetos políticos para 


\section{Tusm Autbahat}

ISSN: 1984-6444 | http://dx.doi.org/10.5902/1984644440290

Estado brasileiro em 1995, via Plano Diretor de Reforma do Aparelho do Estado (PDRAE), na gestão do presidente Fernando Henrique Cardoso (1995-2002).

Pelo até aqui exposto, podemos constatar, com base na leitura das cartas de Recife (2008) e Araxá (2009) (FERESP, 2016), que, nos primeiros anos de atuação, o FERESP buscou consolidar seu papel de agente articulador, necessário, sobretudo, às demandas ali impostas pela economia e pela política para o realinhamento do setor.

Temas como "expansão das matrículas", "financiamento" e "políticas de regulação" figuravam entre os principais assuntos propostos. A partir desse momento, sua atuação política e sua agenda propositiva já demonstravam o fortalecimento da entidade junto ao Estado ao vislumbrar que partes das demandas de políticas públicas que figuravam em sua agenda foram assumidas pela política nacional, sobretudo, em virtude da agenda neoliberal instalada.

Em face do fortalecimento das Entidades Representativas do Ensino Superior Particular, o III CBESP $(2010)^{14}$, cujo tema foi "O setor privado como ator e parceiro na construção do Plano Nacional de Educação (PNE) 2011-2020", destacou que, naquele contexto "a educação superior particular se consolida[va] cada vez mais como força viva e atuante e com um papel de relevo na geração e difusão do conhecimento" (FERESP, 2016, p. 72).

Nesse congresso, o FERESP teve como foco principal a oferta de subsídios para a elaboração do PNE 2011-2020, tentando se firmar no papel de agente articulador frente as novas propostas de políticas públicas para a educação superior. Os objetivos declarados no âmbito do III CBESP eram apoiar e diligenciar políticas para o alcance da meta "de inclusão de $50 \%$ dos jovens com idade entre 18 e 24 anos em cursos superiores. Isso significa o desafio de colocar mais de 12 milhões de estudantes oriundos desta faixa populacional no ensino superior" (FERESP, 2016, p. 72), e participar da construção e da execução do PNE 2011-2020. Com isso, percebese que: 


\section{$\sim$

ISSN: 1984-6444 | http://dx.doi.org/10.5902/1984644440290

O novo PNE traz como eixo central de sua elaboração a mercantilização, a privatização e o empresariamento da educação superior, em um patamar inédito na história deste país, marcado pela presença do fundo público na sustentação do setor privado, pela emergência de grandes conglomerados educacionais, pela abertura de capitais e a consequente desnacionalização das empresas de serviços educacionais. (VALE; CARVALHO; CHAVES, 2014, p. 216)

Nessa direção, figuraram, entre as demandas dessa entidade, as parcerias público-privadas, a criação de sólido programa de cursos tecnológicos, a ampliação do Fies, além do forte trabalho midiático por meio de propagandas que destacavam o importante papel que o setor privado cumpre para a expansão, o fortalecimento e o desenvolvimento da educação superior brasileira.

Um destaque importante nessa carta diz respeito a um dos objetivos a que ela se propôs, o de "lutar pelos direitos assegurados pela Constituição Federal, especialmente os identificados com a livre iniciativa na oferta do ensino [...] e a coexistência de instituições de ensino públicas e privadas" (FERESP, 2016, p. 72). Ou seja, a busca pelo fortalecimento de uma prática política que só se tornou lei com a Constituição Federal de 1988 (BRASIL, 1988).

A LDB de 1996, de acordo com Carvalho (2013), conferiu legalidade à aferição de lucro por uma instituição, legitimando, dessa forma, o privado-mercantil, e contribuindo para o fortalecimento da oferta de educação superior pelas instituições privadas. As políticas que seguiram foram em direção a oligopolização e financeirização do setor, representado, sobretudo, pela abertura do capital de empresas educacionais na bolsa de valores de São Paulo (BOVESPA). 


\section{Tusm

ISSN: 1984-6444 | http://dx.doi.org/10.5902/1984644440290

Gráfico 1 - Expansão das IES Públicas e Privadas de 1996 a 2017.

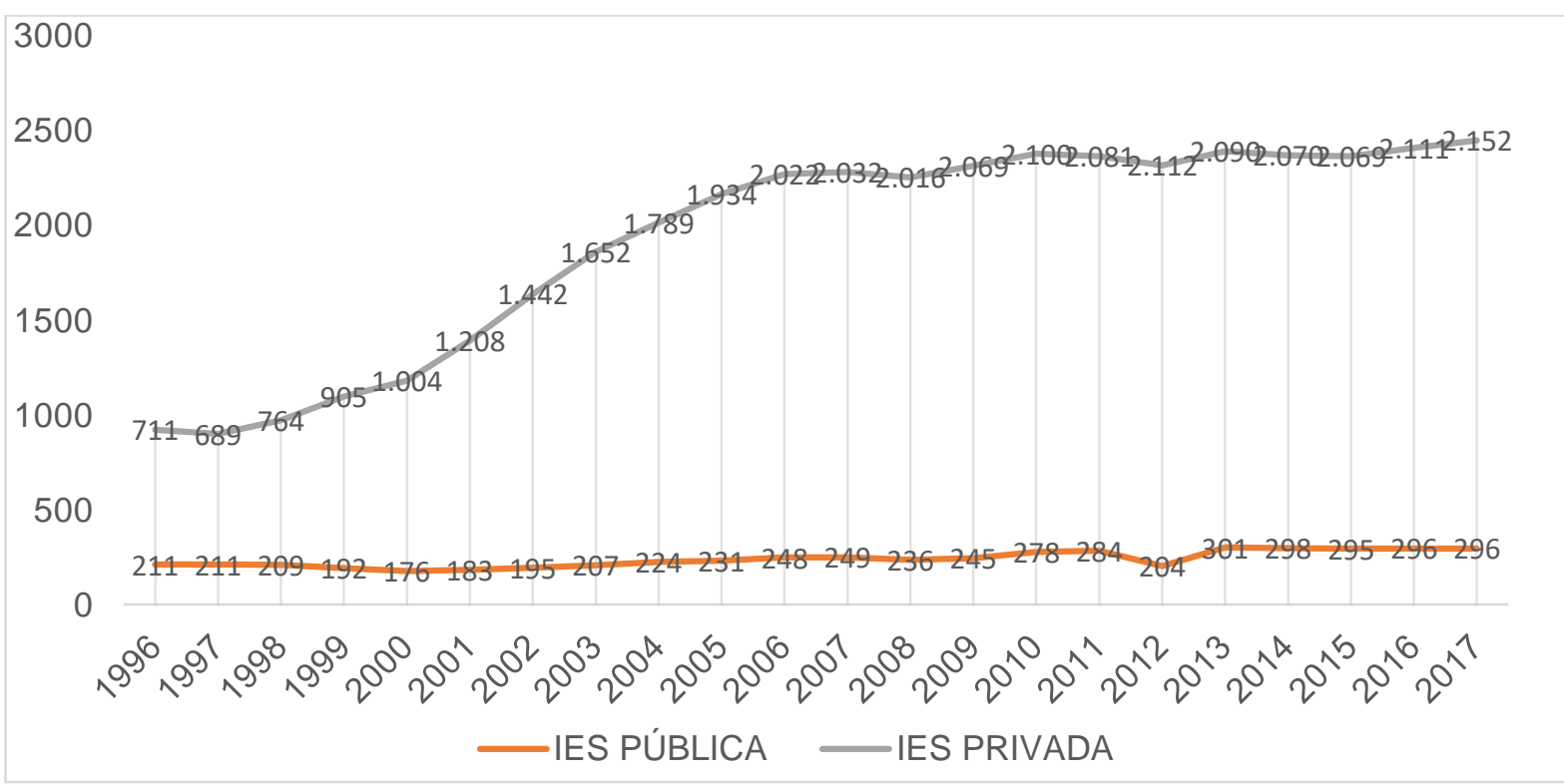

Fonte: Sinopses estatísticas do ensino superior do INEP-MEC de 1996 a 2017.

Conforme Carvalho (2013) destacou, houve uma expansão significativa no que diz respeito ao setor privado no ensino superior, como podemos observar no gráfico acima. Bem como a autora destaca, a partir da oligopolização e da abertura de capital de IES privadas-mercantis, houve a intensificação dessa expansão. De 1996 a 2017, as IES privadas cresceram num percentual de $202,5 \%$ enquanto as IES públicas obtiveram um crescimento em 40,2\% em 21 anos.

No tocante à atuação do Fórum no ano de 2010, sua participação orgânica em reuniões na sede da Anup e da ABMES ocorreu no sentido de deliberar sobre alguns assuntos. São eles: as avaliações dos encontros com ministros e o presidente da Frente Parlamentar; o ingresso de grupos econômicos estrangeiros no controle das IES particulares no Brasil; a melhoria das estratégias na Frente Parlamentar no ano subsequente e apresentação de documento para a Comissão de Transição do governo Dilma Rousseff; e os encaminhamentos de documentos ao ministro Fernando Haddad, principalmente no que diz respeito à "inclusão do Fórum na relação de entidades que indicam nomes para a composição da Câmara de Educação Superior" (FERESP, 2016, p. 15). 


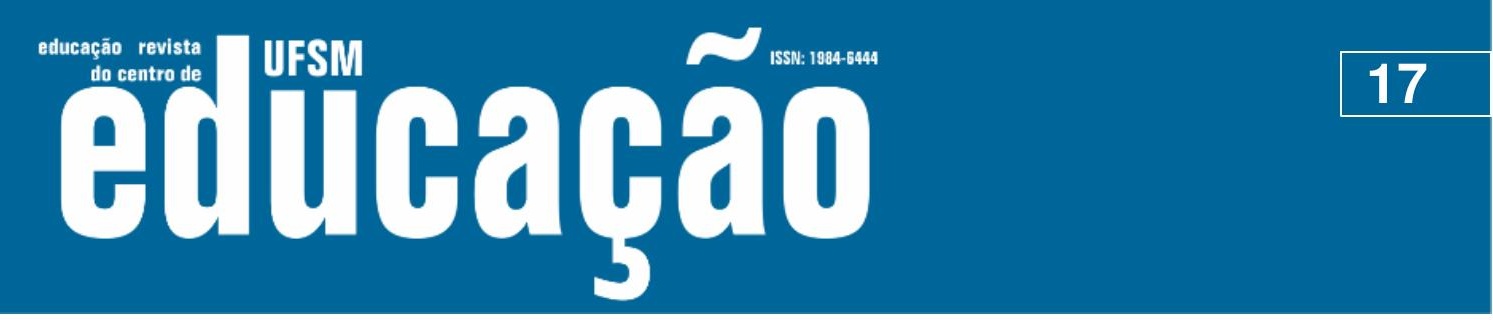

ISSN: 1984-6444 | http://dx.doi.org/10.5902/1984644440290

Ministério da Educação o pedido de liberação do Fies para o Ensino a Distância" (FERESP, 2016, p. 89). Vejamos como a Meta 12 tratou o assunto:

Ampliar, no âmbito do Fundo de Financiamento ao Estudante do Ensino
Superior - FIES, de que trata a Lei no 10.260 , de 12 de julho de 2001 , e do
Programa Universidade para Todos - PROUNI, de que trata a Lei n०11.096,
de 13 de janeiro de 2005 , os benefícios destinados à concessão de
financiamento a estudantes regularmente matriculados em cursos superiores
presenciais ou a distância, com avaliação positiva, de acordo com
regulamentação própria, nos processos conduzidos pelo Ministério da
Educação (BRASIL, 2014).

Em relação à Meta $14^{20}$, parte das deliberações da carta de 2013 também foi acolhida pelo texto do PNE (2014-2024). No âmbito dessa carta, a estratégia era a de reforçar o pedido de liberação da EAD ao MEC. Notemos que a estratégia 14.3 delibera sobre "expandir o financiamento estudantil por meio do Fies à pósgraduação stricto sensu" (BRASIL, 2014). Nesse sentido, fica cada vez mais claro o poder de pressão exercido pelo FERESP sobre o próprio poder legislativo no Brasil.

\section{O novo marco regulatório da educação a distância: proposições do FERESP}

"Ensino superior e novas tecnologias: caminhos e desafios" foi o tema do VII CBESP em 2014 21 . O evento reuniu, novamente, intelectuais de todas as áreas educacionais, "renomados educadores e formuladores de políticas públicas para a educação no Brasil" (FERESP, 2016, p. 91), entre eles estavam Henrique Paim, então ministro da Educação.

Nesse tema acerca dos caminhos e desafios para a educação superior, 0 FERESP se comprometeu em colaborar, articulando-se com o governo em busca de soluções para a Educação a Distância. Esse foi um congresso cujo principal objetivo era diligenciar junto ao MEC aprovações para a implementação do marco regulatório para a EAD e em busca de aumentar seus percentuais de $20 \%$ para $50 \%$.

A partir da manifestação do interesse dessa instituição, é notório o seu poderio ao propor e conseguir melhorias para o setor privado-mercantil ${ }^{22}$. A partir dessa carta, já observamos o FERESP imbricado no Estado, com objetivos e ações concretas para o fortalecimento do setor privado no Brasil. 


\section{T uss

ISSN: 1984-6444 | http://dx.doi.org/10.5902/1984644440290

Para amparar essa discussão, recorremos à Marilena Chauí ao analisar a relação entre capitalismo e direito:

O que marca o neoliberalismo é o desmantelamento de todas as formas de social democracia, portanto, a derrubada da direção dos fundos públicos para os direitos sociais. Todos os direitos sociais são abolidos pelo neoliberalismo, são transformados em serviços. Eles deixam de ser direitos, eles são transformados em serviços e você compra e vende no mercado. A grande privatização neoliberal não é das empresas estatais, a grande privatização é a transformação dos direitos em serviços que você compra no mercado. Feito esse serviço, você vai precisar de uma ideologia que diga que isso é ótimo: “isso não podia ser melhor!". (CHAUÍ, 2017)

\section{Considerações finais}

A mudança de predominância da fração burguesa industrial para a fração burguesa de serviços educacionais, representada pelo FERESP, é o empresariado do ensino expondo justamente os conflitos que existem historicamente no Brasil, no que tange ao ensino superior.

Com a nova reestruturação do capital ocorria a financeirização do ensino superior e os incentivos governamentais por meio de ProUni e Fies, o fortalecimento do setor privado-mercantil, com a abertura de capital, intensificaram a expansão do setor. Por esse motivo, Rodrigues (2007) expõe sobre a (re)articulação do empresariado brasileiro para seguir a lógica da fração burguesa em destaque no momento, o capital financeiro.

A nova fração da burguesia, que são os empresários de ensino, teve seu favorecimento "pela posição estratégica que ocupa na política neoliberal, posto que é herdeira direta da destruição dos serviços públicos, promovida principalmente pelas políticas neoliberais" (RODRIGUES, 2007, p. 127).

Para o autor, existem duas formas de o capital compreender a educação escolar:

[...] educação-mercadoria e mercadoria-educação. Cada uma dessas perspectivas se liga diretamente à forma como o capital busca a autovalorização e cada uma delas é face da mesma moeda, ou seja, são formas sob as quais a mercadoria se materializa no campo da formação humana. (RODRIGUES, 2007, p. 5) 


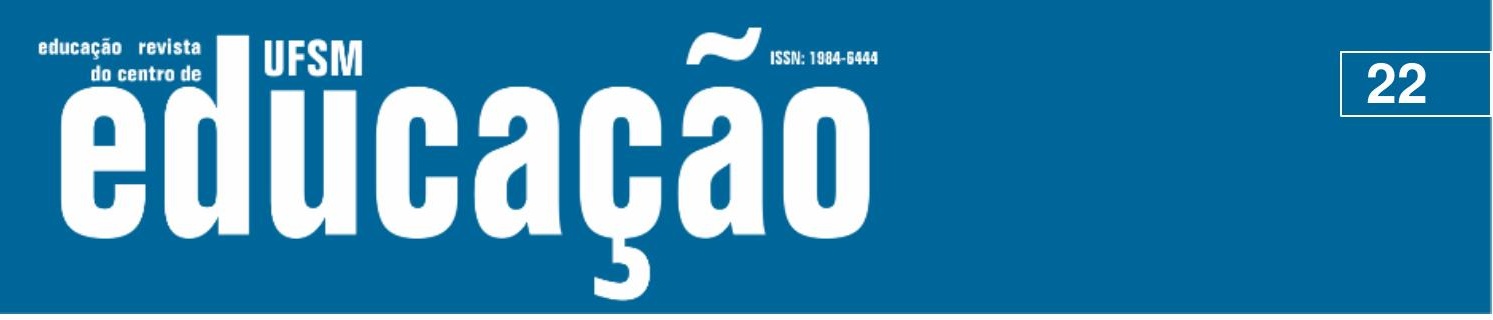

ISSN: 1984-6444 | http://dx.doi.org/10.5902/1984644440290

foram apresentadas oficialmente sob a forma de leis, decretos e portarias normativas que induzem e auxiliam na expansão e no fortalecimento do setor privado.

\section{Referências}

ABMES. CBESP 2019: Na abertura do CBESP, ministro da educação fala em crescimento e liberdade para 0 setor. Disponível em: https://abmes.org.br/noticias/detalhe/3331. Acesso em: 29 Agos. 2019.

ADRIÃO, Theresa; DOMICIANO, Cassia Alessandra. A Educação Pública e as Corporações: avanços e contradições em uma década de ampliação de investimentos no Brasil. FINEDUCA - Revista de Financiamento da Educação, Porto Alegre, v. 8, n. 3, 2018. Disponível em: https://seer.ufrgs.br/fineduca/article/view/79084/47919. Acesso em: 05 Jan. 2019.

BRASIL. Constituição (1988). Constituição da República Federativa do Brasil. Brasília: Senado $\quad$ Federal, $1988 . \quad$ Disponível em: http://www.planalto.gov.br/ccivil_03/constituicao/constituicao.htm. Acesso em: 17 jul. 2018.

BRASIL. LDB. Lei no 9.394, de 20 de Dezembro de 1996[1996a]. Brasília: Congresso Nacional. 1996. Disponível em: http://www.planalto.gov.br/ccivil_03/LEIS/L9394.htm. Acesso em: 14 de Out. 2018.

BRASIL. Lei no 9. 365, de 16 de dezembro de 1996[1996b]. Disponível em: http://www.planalto.gov.br/ccivil_03/LEIS/L9365.htm. Acesso em: 19 dez. 2018.

BRASIL. Lei no 9.780, de 19 de janeiro de 1999. Disponível em: http://www.planalto.gov.br/ccivil_03/Leis/L9780.htm. Acesso em: 19 dez. 2018.

BRASIL. Lei $n^{\circ} 10.260$, de 12 de julho de 2001 [2001a]. Dispõe sobre o Fundo de Financiamento ao estudante do Ensino Superior e dá outras providências. Disponível em: http://www.planalto.gov.br/ccivil_03/LEIS/LEIS_2001/L10260.htm. Acesso em: 06 Abril 2018.

BRASIL. Lei no 10. 183, de 12 de fevereiro de 2001[2001b]. Disponível em: http://www.planalto.gov.br/ccivil_03/Leis/LEIS_2001/L10183.htm. Acesso em: 19 dez. 2018.

BRASIL. LEI № 11.096, DE 13 DE JANEIRO DE 2005. Institui o Programa Universidade para Todos - PROUNI, regula a atuação de entidades beneficentes de assistência social no ensino superior. Disponível em: http://www.planalto.gov.br/ccivil_03/_ato2004-2006/2005/lei/l11096.htm. Acesso em: 19 dez. 2018. 


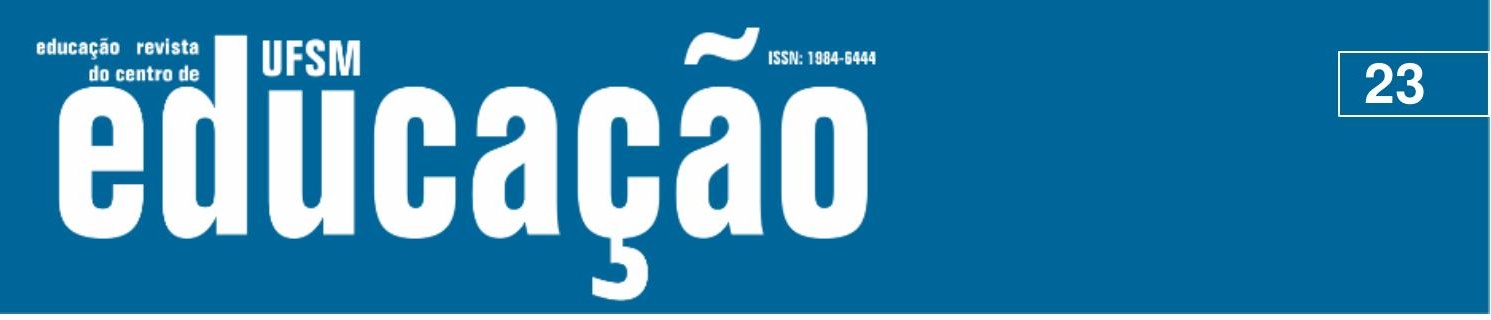

ISSN: 1984-6444 | http://dx.doi.org/10.5902/1984644440290

BRASIL. Lei no 13.005, de 25 de Junho de 2014. Aprova o Plano Nacional de Educação - PNE e dá outras providências. Disponível em: http://www.planalto.gov.br/ccivil_03/_Ato2011-2014/2014/Lei/L13005.htm. Acesso em: 14 Out. 2018.

BRASIL. Decreto no 9.057, de 25 de maio de 2017. Regulamenta o art. 80 da Lei no 9.393, de 20 de dezembro de 1996, que estabelece as diretrizes e bases da educação nacional. $2017 . \quad$ Disponível em: http://www.planalto.gov.br/ccivil_03/_Ato2015-2018/2017/Decreto/D9057.htm.

Acesso em: 13 jun. 2018.

BRASIL. Portaria no 11, de 20 de junho de 2017. Disponível em: http://abmes.org.br/arquivos/legislacoes/Port-Normativa-011-2017-06-20.pdf. Acesso em: 22 dez. 2018.

BRASIL. Portaria no 1.428, de 28 de Dezembro de 2018. Dispõe sobre a oferta, por Instituições de Educação Superior - IES, de disciplinas na modalidade a distância em cursos de graduação presencial. Disponível em: https://abmes.org.br/arquivos/legislacoes/Portaria1428.pdf. Acesso em: 06 Jan. 2019.

BRITO, Ana Paula Batista da Silva. O Fórum das Entidades Representativas do Ensino Superior Particular: um novo intelectual orgânico de base coletiva. Dissertação (Mestrado). 143 f. 2019.

CARVALHO, Cristina. A mercantilização da educação superior brasileira e as estratégias de mercado das instituições lucrativas. Revista Brasileira de Educação v. 18 n. 54 jul.-set. 2013.

CHAUI, Marilena. (30 de janeiro de 2017). O retrato de uma catástrofe. Disponível em: $\quad$ https://www.facebook.com/jornalistaslivres/videos/o-retrato-de-umacat\%C3\%A1strofe/475162479274301/. Acesso em: 08 Jan. 2019.

CURRÍCULO LATTES. Jorge Rodrigo Araújo Messias. Disponível em: http://buscatextual.cnpq.br/buscatextual/visualizacv.do?id=K4485956E8. Acesso em: 14 Jan. 2019.

DIÁRIO OFICIAL DA UNIÃO. Portaria do INEP n 109, de 27 de maio de 2009. Disponível

em: http://download.inep.gov.br/educacao_basica/enem/legislacao/2009/portaria_enem2 009_2.pdf. Acesso em: 19 dez. 2018.

FERESP. Fórum das Entidades Representativas do Ensino Superior Particular. Oito anos trabalhando pela educação brasileira: ações do Fórum das Entidades Representativas do Ensino Superior Particular - período 2008/2016. Brasília: FERESP, 2016. 


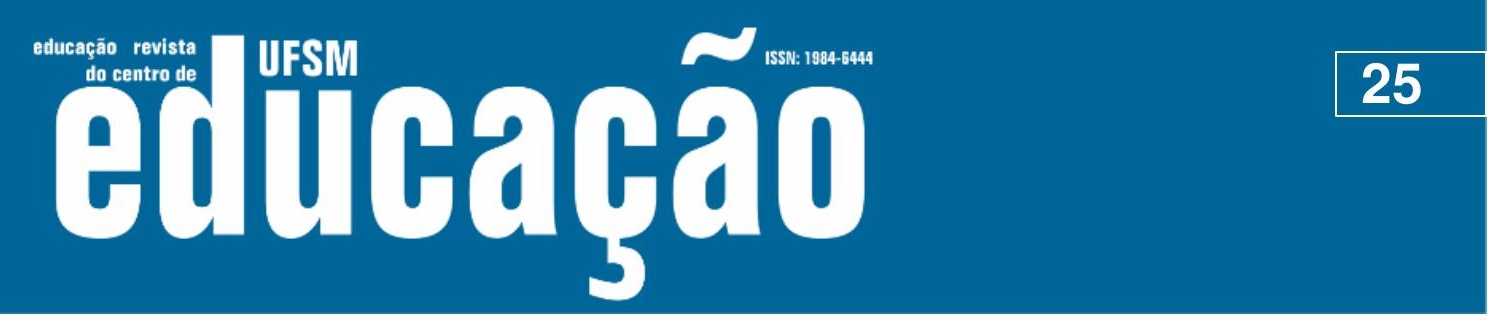

ISSN: 1984-6444 | http://dx.doi.org/10.5902/1984644440290

\title{
Correspondência
}

\author{
Fabíola Bouth Grello Kato — Universidade Federal do Pará — R. Augusto Corrêa, \\ 01 - Guamá, CEP 66075-110, Belém, Pará, Brasil.
}

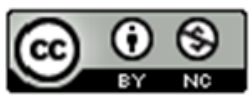

This work is licensed under a Creative Commons Attribution-NonCommercial 4.0
International (CC BY-NC 4.0)

\section{Notas}

\begin{abstract}
${ }^{1}$ A pesquisa que deu origem a este artigo foi defendida em fevereiro de 2019 sob o título "o Fórum das entidades representativas do ensino superior particular: um novo intelectual orgânico de base coletiva". Nessa perspectiva, trabalhamos o conceito de intelectual baseado em Gramsci (2001) ao denominar por intelectuais não apenas a camada entendida por essa denominação, mas toda a massa social que exerce funções organizativas, seja no campo da produção, da cultura ou no campo administrativo-político (GRAMSCI, 2001).
\end{abstract}

${ }^{2}$ Processo de aumento do protagonismo do sistema financeiro, o que consiste basicamente no aumento do poder e da importância dos bancos e instituições afins na gestão e geração de riquezas nas economias capitalistas. A partir daí a renda (em sentido estrito, isto é, o ganho sobre a escassez, a priori, de dinheiro, mas também de imóveis, títulos, etc.) passa a preponderar sobre a forma de riqueza produzida a partir da exploração do trabalho e da produção (VAROUFAKIS, 2016)

${ }^{3}$ Programa Universidade para todos (ProUni) instituído pela Lei no 11.096 , de 13 de janeiro de 2005

${ }^{4}$ Fundo de Financiamento ao Estudante de Ensino Superior (FIES) instituído pela Lei no 13.530, de 07 de dezembro de 2017.

${ }^{5}$ Tomamos a expressão privado-mercantil para diferenciar as Instituições de Educação Superior particulares (com fins lucrativos) e as Instituições de Educação Superior não- lucrativas (filantrópicas e confessionais). Para compreensão conceitual de "privado-mercantil", ler Sguissardi (2008).

${ }^{6}$ José Janguiê Bezerra Diniz (Diretor presidente da ABMES e Presidente do grupo Ser Educacional); Jamil Saud Marques (Vice-presidente de Finanças da Kroton Educacional); Hermes Figueiredo (Presidente do Semesp); Gabriel Mario Rodrigues (Presidente do Conselho de Administração da ABMES); Ronaldo Mota (Chanceler do Grupo Estácio); Daniel Castanho (Presidente da Ânima Educação), entre outros.

${ }^{7}$ Gilberto Gonçalves Garcia (Conselheiro da Câmara de Educação Superior do CNE); Paulo A. Gomes Cardim (Representante da Confenen e Presidente da Conaes); Antonio de Araújo Freitas Júnior, Arthur Roquete de Macedo, Gilberto Gonçalves Garcia e Rafael Lucchesi (Conselheiros do CNE); Henrique Sartori (Secretário da Seres/MEC); Paulo Barone (Secretário da SESu/MEC); William Douglas (Professor e juiz federal brasileiro), entre outros.

${ }^{8} \mathrm{O}$ evento aconteceu em Porto de Galinhas, em Pernambuco, no Beach Class Resort, de 6 a 8 de novembro de 2008.

${ }^{9}$ Esses dados estatísticos apresentados no texto foram retirados de Brasil. MEC. INEP (2013).

${ }^{10}$ Alterou a lei no 9.365, de 16 de dezembro de 1996 (BRASIL, 1996b), que "Institui a Taxa de Juros de Longo Prazo - TJLP, dispõe sobre a remuneração dos recursos do Fundo de Participação PIS-PASEP, do Fundo de Amparo ao Trabalhador, do Fundo da Marinha Mercante, e dá outras providências" (BRASIL, 1999). Depois, foi substituída pela lei $\mathrm{n}^{\mathrm{o}}$ 10.183, de 12 de fevereiro de 2001 (BRASIL, 2001b). 


\section{〜

ISSN: 1984-6444 | http://dx.doi.org/10.5902/1984644440290

${ }^{11}$ Reynaldo Fernandes, Doutor em Economia.

12 O evento ocorreu na cidade de Araxá, em Minas Gerais, no Ouro Minas Grande Hotel e Termas de Araxá, de 18 a 20 de junho de 2009 .

${ }^{13}$ O FERESP propunha que o ProUni levasse em consideração a renda e não a origem do aluno, da rede pública ou privada, e com a proposta de incluir os alunos de cursos de pós-graduação por meio do ProUni.

${ }^{14} \mathrm{O}$ evento aconteceu na cidade de Florianópolis em Santa Catarina, no Costão do Santinho, de 15 a 17 de abril de 2010 .

${ }^{15} \mathrm{O}$ evento aconteceu em Salvador na Bahia, no Hotel Pestana Bahia, de 5 a 7 de maio de 2011.

16 Atualmente, temos a lei $\mathrm{n}^{\mathrm{o}} 13.415$, de 16 de fevereiro de 2017 (BRASIL, 2017), que foi uma conversão da medida provisória $\mathrm{n}^{\mathrm{o}}$ 746, de 2016(BRASIL, 2016).

${ }^{17} \mathrm{O}$ evento aconteceu em Natal, no Rio Grande do Norte, no Natal Grand Hotel, nos dias 14, 15 e 16 de junho de 2012.

${ }^{18} \mathrm{O}$ evento aconteceu em Foz do Iguaçu, no Paraná, no MabuThermas\& Resort, nos dias 6, 7 e 8 de junho de 2013.

19 "Meta 12: elevar a taxa bruta de matrícula na educação superior para 50\% (cinquenta por cento) e a taxa líquida para 33\% (trinta e três por cento) da população de 18 (dezoito) a 24 (vinte e quatro) anos, assegurada a qualidade da oferta e expansão para, pelo menos, $40 \%$ (quarenta por cento) das novas matrículas, no segmento público" (BRASIL, 2014).

20 "Meta 14: elevar gradualmente o número de matrículas na pós-graduação stricto sensu, de modo a atingir a titulação anual de 60.000 (sessenta mil) mestres e 25.000 (vinte e cinco mil) doutores” (BRASIL, 2014).

${ }^{21}$ O evento aconteceu em Maceió, Estado de Alagoas, no Ritz Lagoa da Anta, entre os dias 3 a 5 de abril de 2014.

${ }^{22} \mathrm{O}$ marco regulatório para a EAD foi conquistado em 21 de junho de 2017, aprovado o decreto $\mathrm{n}^{\circ} 9.057$ de 25 de maio de 2017 (BRASIL, 2017).

${ }^{23} \mathrm{O}$ evento foi realizado no Rio de Janeiro, no Royal Tulip, entre os dias 14 e 15 de maio de 2015. 